\title{
Tsunami response in semi-enclosed tidal basins using an aggregated model
}

Susana Bastón ${ }^{1}$, Maitane Olabarrieta ${ }^{2}$, Pedro Lomónaco ${ }^{3}$, Fernando J. Méndez ${ }^{3}$, Raúl Medina ${ }^{3}$

1. ICIT, Institute of Petroleum Engineering, Heriot-Watt University; Old Academy, Back Road Stromness, Orkney KW16 3AW, UK

2. U.S. Geological Survey Woods Hole Coastal and Marine Science Center; 384 Woods Hole Road Woods Hole, MA 02543

3. Environmental Hydraulics Institute. 'IH Cantabria', Universidad de Cantabria. C $\backslash$ Isabel Torres $\mathrm{n}^{\mathrm{o}} 15$

Parque Cientifico y Tecnologico de Cantabria, 39011 Santander, Spain

Corresponding author address

Environmental Hydraulics Institute. 'IH Cantabria'

$\mathrm{C} \backslash$ Isabel Torres $\mathrm{n}^{\mathrm{0}} 15$

Parque Cientifico y Tecnologico de Cantabria

39011 Santander (SPAIN)

Phone: $\quad+34-942-201810$

Fax: $\quad+34-942-201860$

e-mail:mendezf@unican.es

\section{KEYWORDS}

1D model, Tsunami, Coastal lagoon, Coastal flooding, Concatenated bays 


\section{ABSTRACT}

An aggregated model to evaluate tsunami response in semi-enclosed water bodies is presented in this work. The model is based on one-dimensional shallow water equations and can include long-wave external forcing such as a tsunami. It has been successfully validated against experimental data from a physical model, and its predictions for a case study have been compared with results from the COMCOT numerical model. The model can be used as a predictive tool because a calibration using a theoretical value for expansion and contraction losses has been performed, and differences with the typical calibration are less than 10\% which is considered acceptable. This allows using the model in the absence of measured data, which is very difficult to obtain in case of a tsunami event. A case study for the Gulf of Cádiz (Spain) has been simulated with the COMCOT model. The aggregated model predicted the response for a harbor more accurately than for estuarine systems with tidal flats. Nevertheless, the aggregated model has been demonstrated as a useful general tool to predict the response of semi-enclosed tidal basins to a tsunami event, and hybrid models coupling advanced models to simulate ocean tsunami propagation with the model presented here would be useful in developing coastal warning alert systems. 


\section{INTRODUCTION}

Tsunamis, hurricanes and winter storms are the main processes causing the inundation of coastal and estuarine areas. The Asian 2004 tsunami and Hurricane Katrina (2006), which created a tragic loss of life and extensive property damage, are two examples of the most destructive natural phenomena observed in recent years. In order for human communities to exist alongside nature's most destructive forces there is a need for studies of the vulnerability of coastal areas together with long term planning actions to reduce coastal flooding risk.

Along the coast there are many semi-enclosed water bodies (estuaries, coastal lagoons, harbors, etc.) that could potentially be affected by a tsunami. Whatever the size of the water body (lagoon or bay), these are by definition connected to the sea by narrow channels. Modeling long wave propagation towards semi-enclosed water bodies using advanced numerical tools requires a very high grid resolution to include the connection channels. Most of these coastal systems are small enough (on the order of tens of kilometers or less) for the water surface to rise and fall uniformly (co-oscillate) in response to the forcing ocean processes (Defant, 1961). Therefore, the hydrodynamics can be studied using aggregated numerical models.

Aggregated numerical models are based on the one-dimensional shallow water equations, and the name arises from aggregation of geometry, i.e. only a few parameters are required 
to define the geometry of the system (volume, area, mean depth, etc.). Commonly, the estuaries at which this kind of models may be applied are known as Keulegan's bays (Keulegan, 1951), main properties of which are: a) the walls of the bay and inlet are vertical, b) the length of the estuary is shorter than the length of forcing wave, hence bay water level rises uniformly, and c) depth is enough for seabed friction to be neglected.

The proposed model solves the one-dimensional equation of motion and the continuity equation to find the flow velocity through the inlet, the free surface elevation of the bay and the phase lag of the bay relative to the wave in the ocean. The main inputs to the model are a) the bay volume law as a function of water depth and b) the external forcing. Likewise, the model is versatile because it is capable of modeling a wide range of morphologies, from simple bays connected to the sea by a narrow channel to systems with more complex geometries, composed of several bays or connected by culverts under berms or roadways, pipes or other hydraulic structures.

Analytic or idealized models have been generally used to describe tidal propagation towards inner estuaries. Aubrey and Speer (1985), Friedrich and Aubrey (1988) and Friedrich and Madsen (1992) have documented the nonlinear interaction of the offshore tidal constituents, showing how the offshore tide becomes strongly distorted as it propagates into shallow estuarine systems. More recently, Stanev et al. (2003) used a simple analytical theory to perform a volumetric analysis based on the basin hypsometry 
of the Wadden Sea, highlighting that idealized models are helpful to understand the basic processes underlying advanced modeling.

The majority of tidal propagation studies have been applied to single inlet systems. As examples of studies focused on estuaries with more complex geometries can be cited Van de Kreeke $(1988,1990)$ and Salles et al (2005), who studied multiple tidal inlet stability. However, few works have dealt with systems characterized by concatenated bays. Equations for several geometrical configurations of coastal lagoons have been formulated by Jain (2002), but they have not been validated in practice.

The present study aims to improve knowledge about long wave propagation through estuaries, demonstrating that a) one-dimensional equations are able to simulate hydrographical behavior of coastal lagoons even for those with complex geometries, and b) idealized models may be also very useful to predict the response of a tsunami event at semi-enclosed estuaries. The purpose of this study is to develop a simple and fast method to compute the propagation of long waves such as tsunamis into semi-enclosed bays. A hybrid model coupling this aggregated model with advanced models widely used to simulate ocean tsunami propagation, such as MOST (Method Of Splitting Tsunami), developed originally by researchers at the University of Southern California (Titov and Synolakis, 1998), COMCOT (COrnell Multi-grid COupled Tsunami model), developed at Cornell University (Liu et al., 1994) and TSUNAMI2, developed at Tohoko University in 
Japan (Imamura, 1996), would improve the computational effort required for operating early warning systems.

This paper consists of three main parts. In the first part the aggregated model and its equations are introduced both for a single bay estuary and concatenated bays systems. In the second part we describe the validation of the model against experimental data from a physical model of an estuary consisting of three concatenated bays. In the last part results from the aggregated model are compared to the outcomes of the COMCOT model through the application to a case study in the south of Spain.

\section{MODEL DESCRIPTION}

The fundamental concept behind the model presented here is that semi-enclosed basins (Figure 1) are characterized by the trivial fact that the fluid volume change is purely a result of the constant spatial sea-level variations, i.e. the theory of the Helmholtz oscillator (Lighthill 1978). The water volume and related sea-level of the bay change due to the transport of water through the connecting strait. This transport of water is, in turn, driven by the pressure difference, due to a difference in sea-level heights that exists between the entrance and exit of this channel (Maas, 1997). The novelty of this work is that the forcing is not a harmonic function but is instead a solitary wave. 


\section{Aggregated model for a single bay}

The oscillations in a simple inlet-bay system can be described by the following momentum and continuity equations (Bruun et al., 1978):

$$
\begin{aligned}
& \frac{d u}{d t}=\frac{g}{L}\left(\eta_{o}-\eta_{b}-F \frac{u|u|)}{2 g} \dot{\dot{j}}\right) \\
& \frac{d V}{d t}=A_{c} \times u
\end{aligned}
$$

where $g$ is the acceleration due to gravity, $u$ is the current velocity through the inlet, $\eta_{b}$ is the sea-level elevation in the bay and $\eta_{o}$ is the sea-level elevation in the open ocean. The volume of water body can be defined as $V=\int_{0}^{\eta_{b}} A_{b}(z) \times d z$ where $A_{b}$ is the bay horizontal area. Parameters describing the geometrical characteristics of the system are the area of the bay, ${ }_{b}$, the cross-sectional area of the inlet (or channel), $A_{c}$, and the channel length, L. Equations 1 and 2 intrinsically assume that the water oscillations change simultaneously throughout the basin. This implies that the forcing wavelength needs to be bigger than the length scale of the basin-channel system. $F$ is the head loss coefficient defined by Bruun et al. (1978):

$$
F=K+\frac{2 g L}{C^{2} h_{c}}
$$

where $K$ accounts for losses occurring at expansions and contractions, $L$ has been already defined as the channel length, $h_{c}$ is the channel depth below mean sea level and $C$ is the Chezy coefficient, which has been assumed to be $45 \mathrm{~m}^{1 / 2} / \mathrm{s}$. The second term of the 
right side of the equation (3) represents the friction losses through the channel, while the parameter $K$ includes the head losses associated to expansion and contraction of the flow, commonly known as minor losses (Chanson, 1999). Those losses are related to turbulent processes (i.e., formation of eddies); therefore, they are usually estimated empirically, and $K$ can be treated as a calibration parameter.

Let us assume that the cross-sectional area of the inlet is a linear function of depth:

$$
A_{c}=A_{c}^{0}\left(1+\frac{\eta_{c}}{h_{c}}\right) \text { 市, }
$$

where $A_{c}^{0}=W_{c} \rtimes_{c}$, and $W_{c}$ is the inlet width at mean sea level. The free surface at the channel $\left(\eta_{c}\right)$ changes along the tidal cycle and it depends on the open ocean sea level $\left(\eta_{o}\right)$.

For simplicity, the side walls can be assumed as vertical and therefore the bay area, ${ }^{A_{b}}$, is constant. Hence, $V=A_{b} \rtimes_{b}$, and equations (1) and (2) will become:

$$
\begin{aligned}
& \frac{d u}{d t}=\frac{g}{L}\left(\eta_{o}-\eta_{b}-F \frac{u|u|}{2 g} \stackrel{?}{\dot{j}}\right) \\
& \frac{d \eta_{b}}{d t}=\frac{A_{c}}{A_{b}} \rtimes_{u}
\end{aligned}
$$

Thus, (5) and (6) are a system of two differential equations with two unknowns, ${ }^{u(t)}$ and $\eta_{b}(t)$, which depends on the time-dependent open sea surface elevation, ${ }^{\eta_{o}(t)}$. These 
equations are solved numerically using a Runge Kutta method with a variable time step for efficient computation.

Usually, $\eta_{o}$ represents a tidal wave by means of a harmonic function. However, because we are developing a model to simulate the tsunami-induced wave propagation, forcing is described by an analytical expression for a solitary wave (7) that reproduces the main behavior of the first wave of a tsunami (Liu et al., 1994). The expression used to describe the temporal variation of the free surface elevation of a tsunami wave is

$$
\eta_{o}(t)=H \operatorname{sech}^{2}\left[\frac{3}{4} \frac{H}{h^{3}} \times c t\right]
$$

where $H$ is the wave height in open sea, $h$ is the water depth at the mean sea level in open waters, $t$ is time and $c$ is the wave celerity, which has been defined by

$$
c=\sqrt{\frac{g h}{1-(H / h)}}
$$

\section{Equations for systems of concatenated bays}

The main strengths of aggregated models are that the input data can be easily prepared and that their application has sufficient accuracy for engineering planning and design. Due to their simplicity they can be easily applied to systems covering multiple geometries. Open channels can have prismatic, parabolic or irregular sections; closed conduits can have circular, rectangular or other shapes, but systems consisting of several water bodies interconnected can also be modeled. To illustrate this aspect, the model has 
been validated against a physical model with three concatenated bays, i.e. bays connected in a raw (see lower panel in Figure 1). The equations for this type of estuarine systems are given by $n$ momentum equations (9) and $n$ continuity equations (10), where $n$ is the number of bays of the system and ${ }^{i}$ the index that represents each bay individually.

$$
\begin{aligned}
& \frac{d u_{i}}{d t}=\frac{g}{L_{i}}\left(\eta_{i-1}-\eta_{i}-F_{i} \frac{u_{i}\left|u_{i}\right|}{2 g} \underset{\dot{j}}{\dot{j}} \text { for } \mathrm{i}=1,2, \ldots, \mathrm{n}\right. \\
& \frac{d \eta_{i}}{d t}=\frac{A_{c i}}{A_{b i}} u_{i}-\frac{A_{c i+1}}{A_{b i}} u_{i+1} \text { for } \mathrm{i}=1,2, \ldots, \mathrm{n}-1 \\
& \frac{d \eta_{i}}{d t}=\frac{A_{c i}}{A_{b i}} u_{i} \text { for } \mathrm{i}=\mathrm{n}
\end{aligned}
$$

The water level in the last bay $(i=n)$ depends only on the flux through the inlet which connects this bay with the previous one. However, water level in the intermediate bays (from 1 to $n$-1) depends on the flux exchanged with the preceding and following bay, including the open ocean (bay 0).

\section{Comparison with experimental data}

Tsunamis are events occurring very rarely and therefore, validating numerical models with field measurements is very difficult. Further, reliable measurements are very scarce due to the unpredictable character of tsunami events in time and in unknown or remote locations. As an alternative, the proposed numerical model has been validated using an experimental physical model. 


\section{Experiment description}

The experiments were performed in the wave basin of the Coastal and Ocean Laboratory, Environmental Hydraulics Institute, 'IH Cantabria', in Spain. The wave basin is $28.4 \mathrm{~m}$ long, $8.6 \mathrm{~m}$ wide and $1.2 \mathrm{~m}$ deep. It is equipped with a multi-board electric-drive piston wave maker. This wave maker has ten paddles, $85 \mathrm{~cm}$ wide each, with a maximum stroke of $1 \mathrm{~m}$ and the total installed power is $100 \mathrm{~kW}$. Although the main function of the wave maker is the generation of short period waves, the control system and paddle geometry allows the generation of long waves with periods exceeding $20 \mathrm{~s}$ and wave heights between 5 and $10 \mathrm{~cm}$, depending on the water depth. Moreover, power is sufficient to generate solitary waves with height up to $50 \%$ of the water depth at the wave maker.

The physical model layout was composed of three interconnected bays in series. Bays 1 and 2 were $1.5 \mathrm{~m}$ x $1.5 \mathrm{~m}$ while bay 3 was $1.5 \mathrm{~m}$ wide and $1.25 \mathrm{~m}$ long. The inlet widths were, respectively, 21.5, 11.5 and $5.5 \mathrm{~cm}$. Bays were located in the centre of the basin, over a $23 \mathrm{~cm}$ high concrete horizontal platform, which simulates a constant depth floor. The water depth was $15 \mathrm{~cm}$. The platform was preceded by a mild 1:20 shoaling slope, equivalent to the continental shelf; so shoaling effects were represented by the wave propagation into shallow waters. The regularization zone, from the wave maker to the toe of the slope, was $5.4 \mathrm{~m}$ long, and the model first inlet was located $3 \mathrm{~m}$ from the end of the shoaling slope, providing a space of more than $13 \mathrm{~m}$ from the wave maker to the model. The model was also bounded by a highly dissipative gravel slope to avoid undesired 
reflections. In Figure 2, the layout of the multi-connected bay system in the basin is shown, and the location of the wave gauges is also depicted.

A 12-bit data acquisition board was used to record the surface elevation time series. Resistive-type wave gauges can resolve up to 4096 increments within the calibration range, i.e. a theoretical resolution of less than $0.1 \mathrm{~mm}$ in a $10 \mathrm{~cm}$ calibration range. In practice, the actual resolution of the gauges accepted is approximately $0.5 \mathrm{~mm}$, mainly due to surface tension effects. One sensor (S2 station of Figure 2) was placed $1 \mathrm{~m}$ outside the inlet in order to measure the forcing wave's characteristics. Another two gauges (S3 and S4) were placed inside bay 1 and two more (S5 and S6) inside bays 2 and 3 respectively.

A standard procedure for solitary wave generation was applied. The wave maker was controlled by its position, and the stroke time series was derived directly from eq. (7) as described fully in Hughes (1993). For comparison purposes, in Figure 3 the theoretical profile of a $3 \mathrm{~cm}$ solitary wave was shown with the measured surface elevation at the regularization zone. The arrival, rise and crest of the solitary wave was properly generated by the wave maker, while the symmetric branch of the wave was already affected in the measurement by the reflections of the shoaling ramp and model. Nevertheless, since the model allows the introduction of an arbitrary wave profile, the measured surface elevation in front of the first inlet has been introduced as boundary 
condition into the model, regardless of the presence of asymmetries, solitons or scattered waves.

\section{Numerical model validation}

The same physical conditions as in the laboratory experiments were modeled using the aggregated model. The forcing in the numerical runs were those measured outside the bay system. The solitary wave amplitude decreased when it arrived in the different bays (Figure 4). The heights outside of the system and in each bay were $2.13 \mathrm{~cm}, 1.36 \mathrm{~cm}$, 0.76 and $0.61 \mathrm{~cm}$, respectively. This is a consequence of the inlet width of the physical model becoming narrower from bay 1 to 3 , hence the volume of water going through consequent bays was declining and thereby the amplitude of the solitary wave was lower. There is also a small phase lag between the different bays, caused mainly by the finite wave speed of the incoming solitary wave. It is also noteworthy that the level variations measured outside the system after the soliton (the tail of the solitary wave) had also a response inside each bay.

Usually, the calibration parameter $K$ must be evaluated by comparison of modeled and measured data, finding the value of $K$ that minimizes the difference between them. This is called typical calibration. Because it is difficult to obtain data with which to compare model outputs, an assessment of the model assuming a theoretical value of the calibration parameter has been performed, henceforth referred to as blind calibration. For 
engineering purposes the most typical value for the local head loss coefficient in problems of large wave propagation through enclosed sections is $K=1.0$ (Blevins, 1992).

Typical calibration is based on the calculation of the root mean square error $\varepsilon_{r m s}$ between experimental and modeled data for each bay. Because there is a local head loss coefficient for each bay $\left(K_{1}, K_{2}, K_{3}\right)$, the calibration process consists in looking for the combination of these coefficients that minimizes the error. The optimal combination that minimizes $\varepsilon_{r m s}$ is given by $K_{1}=1, K_{2}=0.9$ and $K_{3}=0.55$. The results from blind calibration (Figure 4) show that the numerical model reproduces for all bays, not only the initial soliton but also the following water level fluctuations, both elevation and depression of the water surface. The $\varepsilon_{\text {rms }}$ between measured and modeled data (indicated in Table 1) ranges from 1 to $4 \%$ of input wave for both types of calibration. The difference of ${ }^{\varepsilon_{r m s}}$ between the two is less than $10 \%$. Therefore, the commonly assumed value of local head loss coefficient $K=1$ is suitable to reproduce the response of a tsunami inside a bay and identify the proposed numerical model as a predictive tool.

\section{Comparison with COMCOT Model}

In this section the performance of the aggregated model as a suitable and useful tool for flood detention is assessed by comparing the results of the aggregated model with those obtained from the COMCOT (COrnell Multigrid COupled Tsunami) model, (Liu et al., 1994) implemented for the Gulf of Cadiz. This is one of the areas that are most sensitive 
to tsunamis in Spain, due to the proximity of the Gottinge Bank, the eastern end of the Azores-Gibraltar Fracture, which is considered to be the boundary between the Eurasian and African plates (Gjevik et al 1997).

The COMCOT model is a finite-difference Non Linear Shallow Water (NLSW) tsunami code, able to simulate the generation, propagation and run-up of earthquake or landslide generated tsunamis. This model has been used to investigate several historical tsunamis, such as the 1960 Chilean tsunami (Liu et al., 1994) and the Sumatra tsunami in 2004 (Wang and Liu, 2006). It uses an explicit leap-frog finite difference scheme to solve the shallow water equations.

The case study simulated in this paper corresponds to one of the worst tsunami generation scenarios in the Gulf of Cadiz region. Omira et al (2009) have studied the tsunamigenic potential of this area that could affect coasts of Portugal, Spain and Morocco. Here we are modeling with the COMCOT a seabed displacement of the Horseshoe/Marques de Pombal faults, so it was assumed that the epicenter was located at $36^{\circ} \mathrm{N}$ and $10.5^{\circ} \mathrm{W}$ with a $216 \mathrm{~km}$ long and $70 \mathrm{~km}$ wide surface of tectonic drift. The focal depth was $40 \mathrm{~km}$, and vertical displacement of ocean floor was $14 \mathrm{~m}$. Fault geometry was described by strike, dip and rake, which were respectively $48^{\circ}, 35^{\circ}$ and $90^{\circ}$. The simulated time was two hours and required 125 hours of CPU time. 
The main strength of this model is that it allows the use of embedded grids, i.e. there is a fine grid for the objective area inside a coarse grid for open sea. To simulate the propagation of this tsunami from the source region to Cadiz and assure a good description of bathymetric and topographic effects near shore, a system of three nested grids with 800,200 and $50 \mathrm{~m}$ resolution was used. The locations and extensions of each of the considered grids are shown in Figure 5. The finer grid is focused on the target areas, namely Cadiz Harbor and Bay.

The major aim of this section is to analyze the response of this tsunami in two semienclosed water bodies, the Bay of Cadiz (case A) and the Cadiz harbor (case B). The former has large tidal flats; however the characteristics of the latter are closer to Keulegan bays; i.e. owing to it being small and without differences in depth a co-oscillation response throughout the basin may be expected. Several control points were chosen inside both coastal systems to evaluate the results of COMCOT (lower panel of Figure 5). In order to validate the aggregated model, the free surface variation on both case studies has been compared against the mean value of the control points for each basin.

Implementation of the aggregated model requires the definition of the time-dependent sea-level outside of the systems, which in this case is the elevation from the COMCOT model at point 1 , and the description of the geometrical characteristics of both systems, i.e. flooding law of the basin, and length and cross-sectional area of the inlet. In both cases it has been assumed that the inlets have a rectangular section. The area in case B is 
$1275000 \mathrm{~m}^{2}$, bounded by vertical walls, thus the area is constant. The inlet is $285 \mathrm{~m}$ wide, $10 \mathrm{~m}$ deep and $500 \mathrm{~m}$ long. The tidal inlet length is estimated as the effective length of the jet generated by a uniform flow in the strangulated water body. In case A, it is not possible to assume that the boundaries are vertical; hence a polynomial expression has been used for $A_{b}(z)$. The inlet is $5560 \mathrm{~m}$ long, $1000 \mathrm{~m}$ wide and $12.5 \mathrm{~m}$ deep. The local head loss coefficient $(K)$ has been assumed to be equal to 1.0 , since has already been demonstrated that this value is suitable for using the model as a predictive tool. The simulation characteristics were the same as for COMCOT model, two hours using a time step of $20 \mathrm{~s}$. In comparison with the advanced model the computational effort of the aggregated model is negligible; it took less than $10 \mathrm{~s}$ CPU time.

Elevation for each control point computed by COMCOT, and the average against which the aggregated model has been compared, is shown in Figure 6. The difference in response between the two cases is noteworthy. The free surface variation in the harbor is similar to the wave outside. Nevertheless, in case A because of the frictional effects induced by the channel connecting the Bay of Cadiz with the sea, it takes the wave twenty minutes to propagate into the bay. The wave shape is modified, having a smaller amplitude and longer wave period than outside the system. In Bay of Cadiz the spatial variation of the free surface elevation is larger than in the harbor, mainly because there are tidal flats and hence the spatial variation of depth affects the spatial response of the sea level. 
Figure 7 shows the comparison between the spatially averaged free surface elevation computed with COMCOT and the results of the aggregated model for both case of study. In case $\mathrm{A}$ the ${ }^{\varepsilon_{r m s}}$ between solutions of the two models is $10.7 \mathrm{~cm}$. Simulation from the aggregated model shows that the fall in the level preceding the solitary wave occurs ten minutes earlier than predicted by COMCOT. Omira et al (2009) concluded that the arrival time difference between linear and non linear computations of the same tsunami was about six minutes. Therefore the error derived by using an aggregated model instead of an advanced model is within an acceptable order of magnitude. There is also a difference between the lengths of flooding - the COMCOT simulation shows that it takes 17 minutes while the crest of the soliton predicted by the aggregated model lasts seven minutes before starting to fall. Nevertheless, elevation is correctly modeled by the aggregated model; the difference with COMCOT is $8 \mathrm{~cm}$ for the lowest level and $6 \mathrm{~cm}$ for the highest. In case B, the aggregated model reproduces better the mean solution of COMCOT model than in case $\mathrm{A}$, the ${ }^{\varepsilon_{r m s}}$ being $8.1 \mathrm{~cm}$. Further research is needed to find the reason of the discrepancy in case A; the assumption of pressure loss coefficient $K=1$ is suitable for basins with vertical walls such as the laboratory test and case B of this section, but the geometry of case A is not so simple, and possibly there is a combination of parameters that restricts the application of the aggregated model, such as, for example, the relation between bay and channel lengths.

\section{SUMMARY AND CONCLUSIONS}


In this work, the response of a semi-enclosed coastal system for a tsunami-induced wave using an aggregated model has been analyzed. In general, the approximate solution from the aggregated model is useful for engineering purposes and could be very helpful in high risk situations where a rapid assessment of the hydrodynamic response of an estuary is required.

This model has been successfully validated against experimental data from a physical model, and its predictions for a case of study have been compared with results from the COMCOT numerical model. The aggregated model was able to reproduce the propagation of tsunami waves in semi-enclosed water bodies. Because the physical model was composed of three concatenated bays, this work validates the equations of conservation of the moment and continuity for multiple-bay systems. The ${ }^{\varepsilon_{r m s}}$ between laboratory data and numerical model results was ranged from 1 to $4 \%$ of the input wave. Because the simulations in which $\mathrm{K}$ was assumed to be 1 also gave RMS errors in this range, the model can be used to predict the effects of tsunamis even when measurements are sparse.

A case study for the Gulf of Cádiz (Spain) has been simulated using the COMCOT model. Comparison of the aggregated model with this advanced model shows that the aggregated model response provides a better fit to the results of the advanced model for simplified coastal systems such as harbors than for estuarine systems with tidal flats. 
In applying the aggregated model to emergency systems (i.e. tsunami alert tools) to protect coastal areas, which requires a rapid answer, it is sensible to use a coupling to advanced numerical models that provide it the external forcing. Therefore, we recommend the use of hybrid systems, composed of complex hydrodynamic models of generation and propagation of tsunamis and aggregated models to downscale sea-level variations in semi-enclosed water bodies. 


\section{ACKNOWLEDGMENTS}

The authors wish to thank two anonymous reviewers whose detailed comments greatly improved the quality of this manuscript. 


\section{REFERENCES}

AuBREY, D.G. AND SPEER, P.E. (1985). “A study of non-linear tidal propagation in shallow inlet/ estuarine systems Part I: Observations”. Estuarine, Coastal and Shelf Science, 21, p. $185-205$

Blevins, R.D. (1992). Fluid Dynamics Handbook. Krieger Publishing Company

Bruun, P., Mehta, A.J. And Jonsson, I.G. (1978). Stability of Tidal Inlets: Theory and Engineering. Elsevier Scientific Publishing Co., Amsterdam. The Netherlands.

Chanson, H. (1999), The Hydraulics of Open Channel Flow, Arnold, London

Defant A. (1961). Physical Oceanography, Vol. 1. New York: Pergamon. 598 pp.

FRIEDRICHS, C.T. AND AUBREY, D.G. (1988). "Non-linear tidal distortion in shallow well-mixed estuaries: a synthesis". Estuarine, Coastal and Shelf Science, 27, p. 521-545.

FriedRICHS, C.T., MADSEN, O.S., (1992). "Nonlinear diffusion of the tidal signal in frictionally dominated embayments". J. Geophys. Res. 97 (C4), 5637-5650 
GJEVIK B. et al. (1997), "Modeling tsunamis from earthquake sources near Gorringe Bank southwest of Portugal," Journal of geophysical research, vol. 102, no. 13, pp. 27931-27, 949

Hughes, S. A., (1993). Physical models and laboratory techniques in coastal engineering. World Scientific Publ. Co. Ltd.

IMAMURA, F. (1996) “Review of tsunami simulation with a finite difference method," Longwave run-up models, pp. 25-42

JaIn, M. (2002). Hydraulics and stability of Multiple-Inlet bay systems: St. Andrew Bay, Florida. Thesis for the Degree of Master of Science. University of Florida.

KeUlegan, G.H. (1951). Third progress report on tidal flow in entrances. Water level fluctuactions of basins in communication with seas. Report 1146, National Bureau of Standards D, $32 \mathrm{pp}$

Lighthill (1978). Waves in fluids. Cambridge University Press, Cambridge

LiU, P.L.-F., Cho, Y-S., Yoon, S.B. AND SeO, S.N. (1994). "Numerical simulations of the 1960 Chilean tsunami propagation and inundation at Hilo, Hawaii”. In: Y. Tsuchiya and N. Shuto, (Eds.), Tsunami: Progress in Prediction, Disaster Prevention and Warning. Kluwer Academic Publishers, pp. 99-115. 
MAAS, L.R.M. (1997). “On the nonlinear Helmholtz response of almost-enclosed tidal basins with sloping bottoms”. J. Fluid Mech. 349, pp. 361-380.

OMiRA, R. et al. (2009), "Design of a sea-level tsunami detection network for the Gulf of Cadiz," Nat. Hazards Earth Syst. Sci, vol. 9, pp. 1327-1338

SAlles, P., Voulgaris, G. AND Aubrey, D.G. (2005) "Contribution of nonlinear mechanisms in the persistence of multiple tidal inlet systems," Estuarine, Coastal and Shelf Science, vol. 65 , no. 3, pp. $475-491$

SpeER, P.E., AND AubreY, D.G. (1985). “A Study of Non-Linear Tidal Propagation in Shallow Inlet/Estuarine Systems; Part II: Theory”. Estuarine, Coastal and Shelf Science, Vol 21, pp 207-224.

StAnev, E.V., FlöSER, G. AND WolfF, J.-O. (2003a). "Dynamical control on water exchanges between tidal basins and the open ocean. A case study for the East Frisian Wadden Sea". Ocean Dynamics 53, 146-165.

Stanev, E.V., Wang, Z.B.; Capobianco, M.; Ruol, P.; Buijsman, M.C (2003b). "On the circulation in the East Frisian Wadden Sea: numerical modelling and data analysis". Ocean Dynamics 53, 27-51. 
Titov, V.V AND SynOlaKis, C.E. (1998), “Numerical modeling of tidal wave runup,” Journal of Waterway Port Coastal and Ocean Engineering, vol. 124, no. 4, pp. 157-171.

van DE KReEke, J. (1988). "Hydrodynamics of Tidal inlets". In: Hydrodynamics and Sediment Dynamics of Tidal Inlets, Coastal and Estuarine Studies 29. Edited by D.G. Aubrey and L. Weishar. Springer-Verlag, New York.

van de Kreeke, J., (1990). “Can multiple tidal inlets be stable?” Estuar. Coast. Shelf Sci. vol. $30,261-273$

WANG, X. AND LiU, P.L.-F. (2006). "An analysis of 2004 Sumatra Earthquake fault plane mechanisms and Indian Ocean Tsunami”. Journal of Hydraulic Research, vol.44, n 2, pp. $147-154$. 


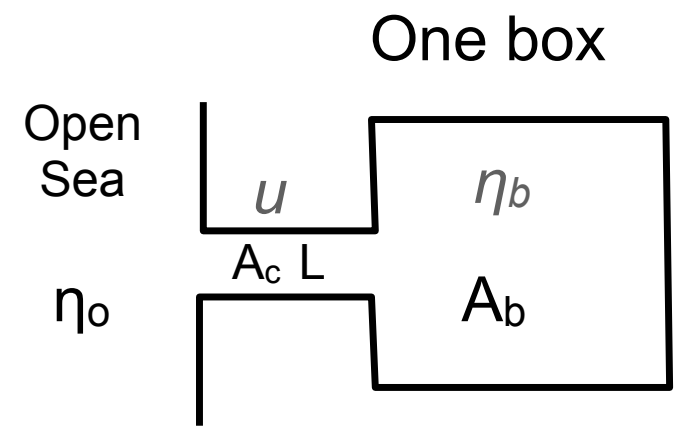

Three concatenated boxes

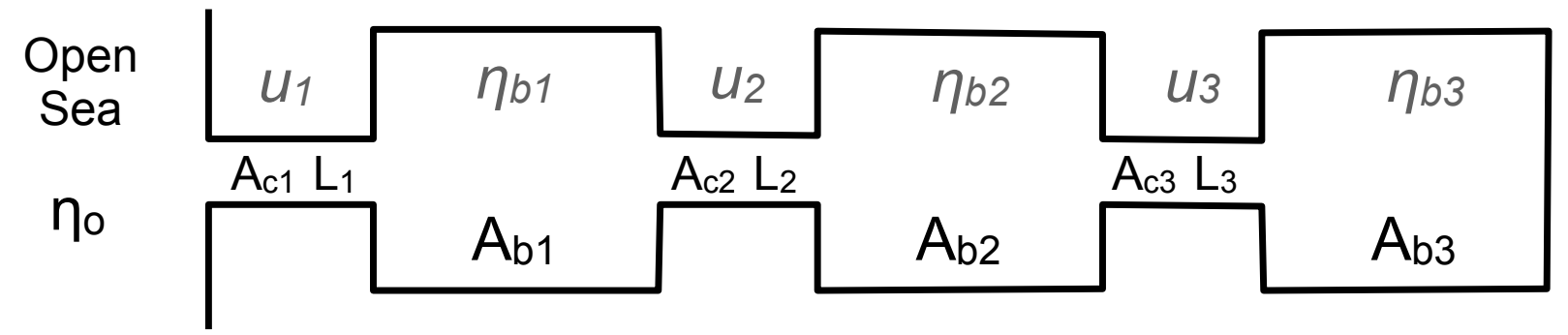




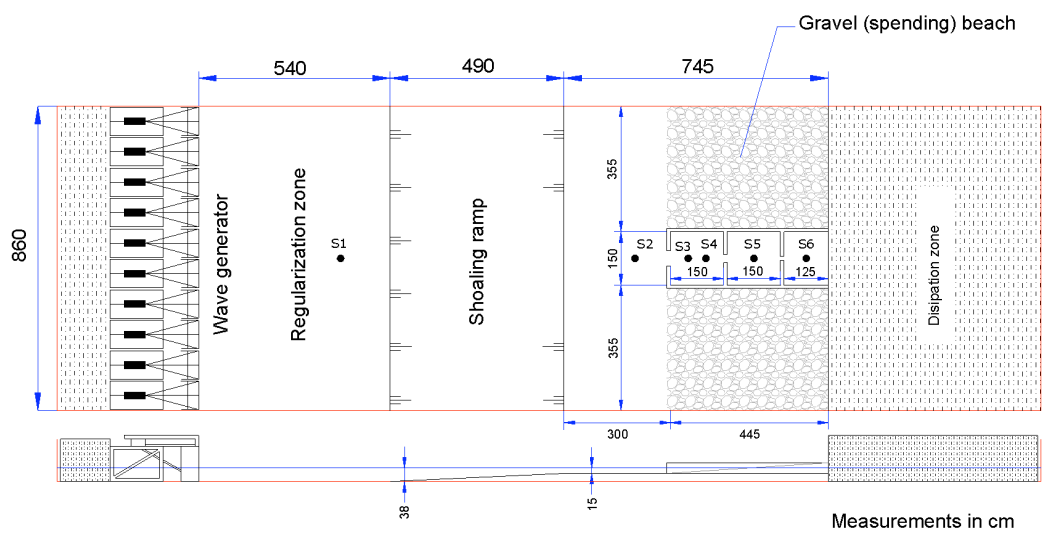




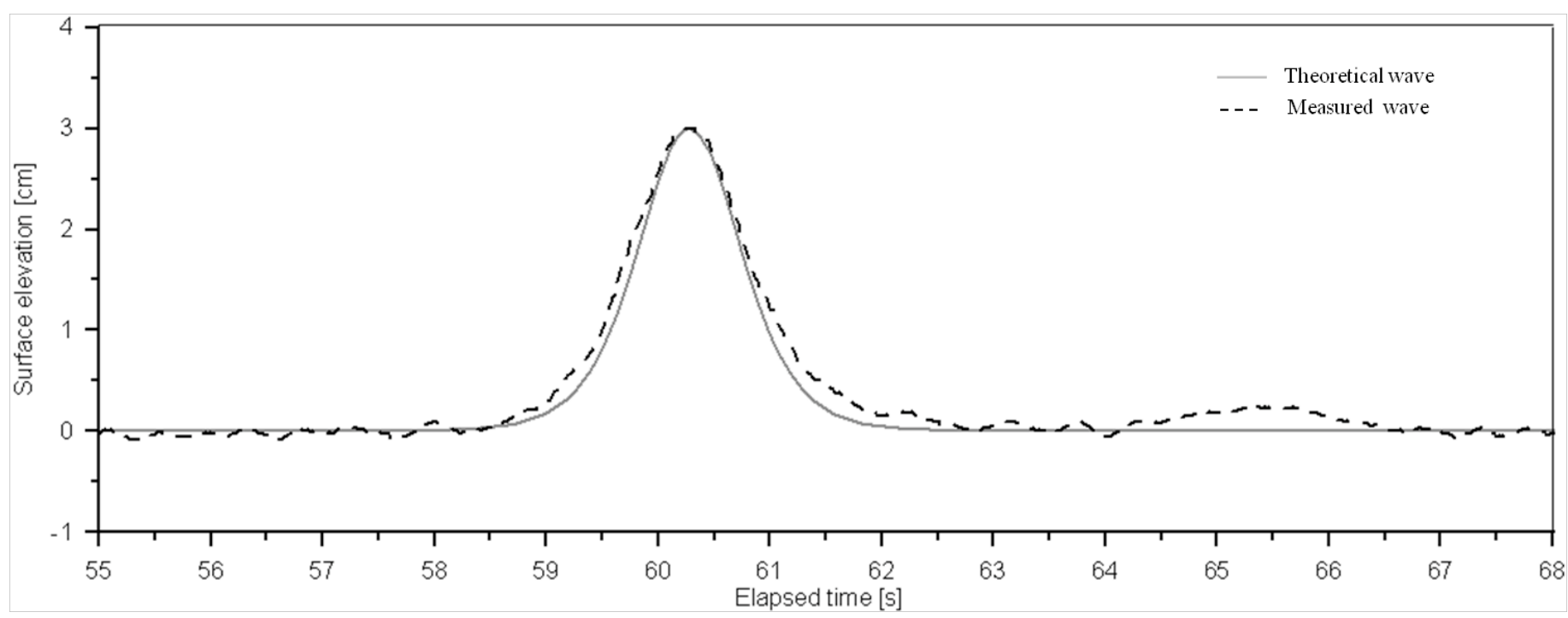



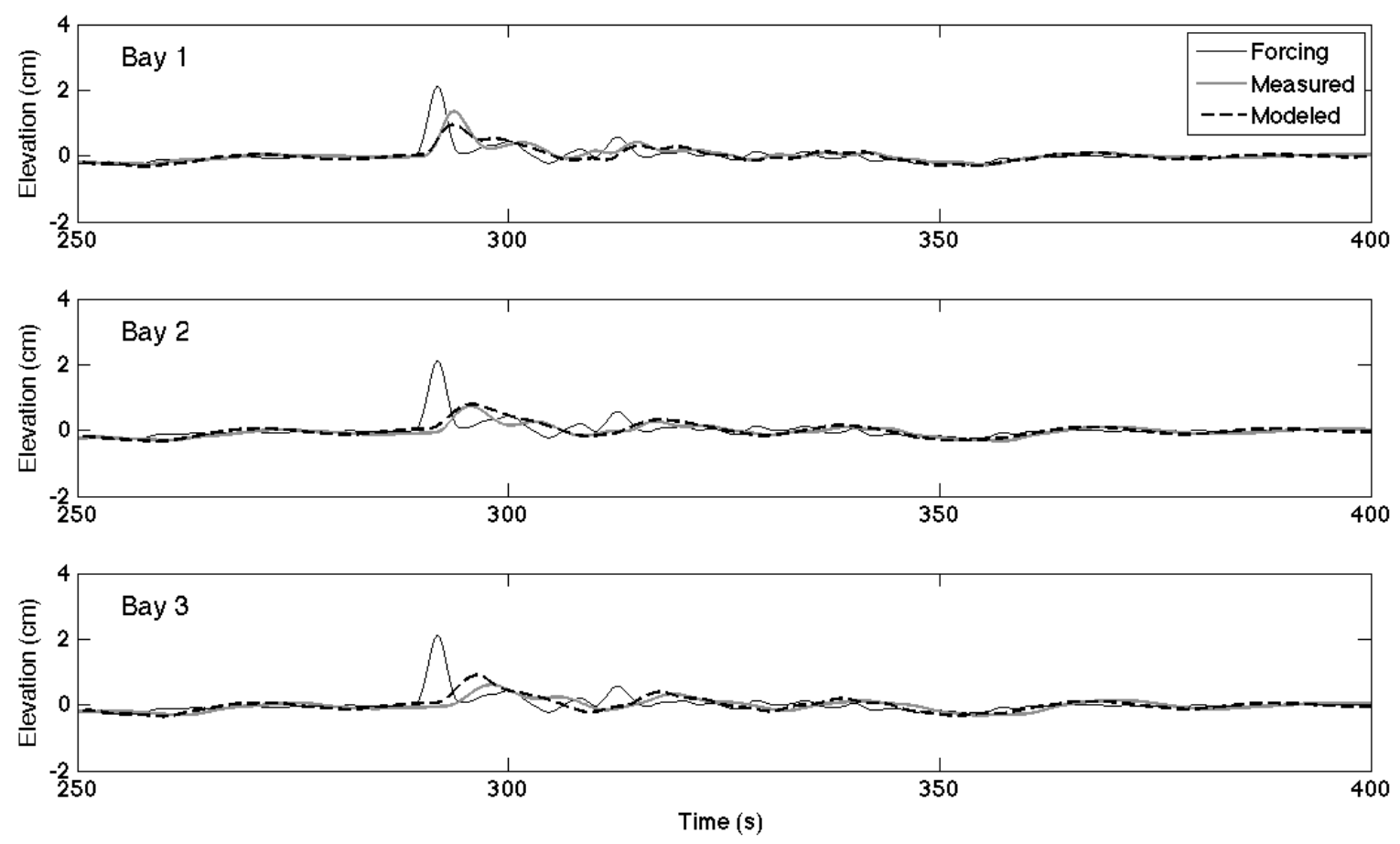
Click here to download high resolution image
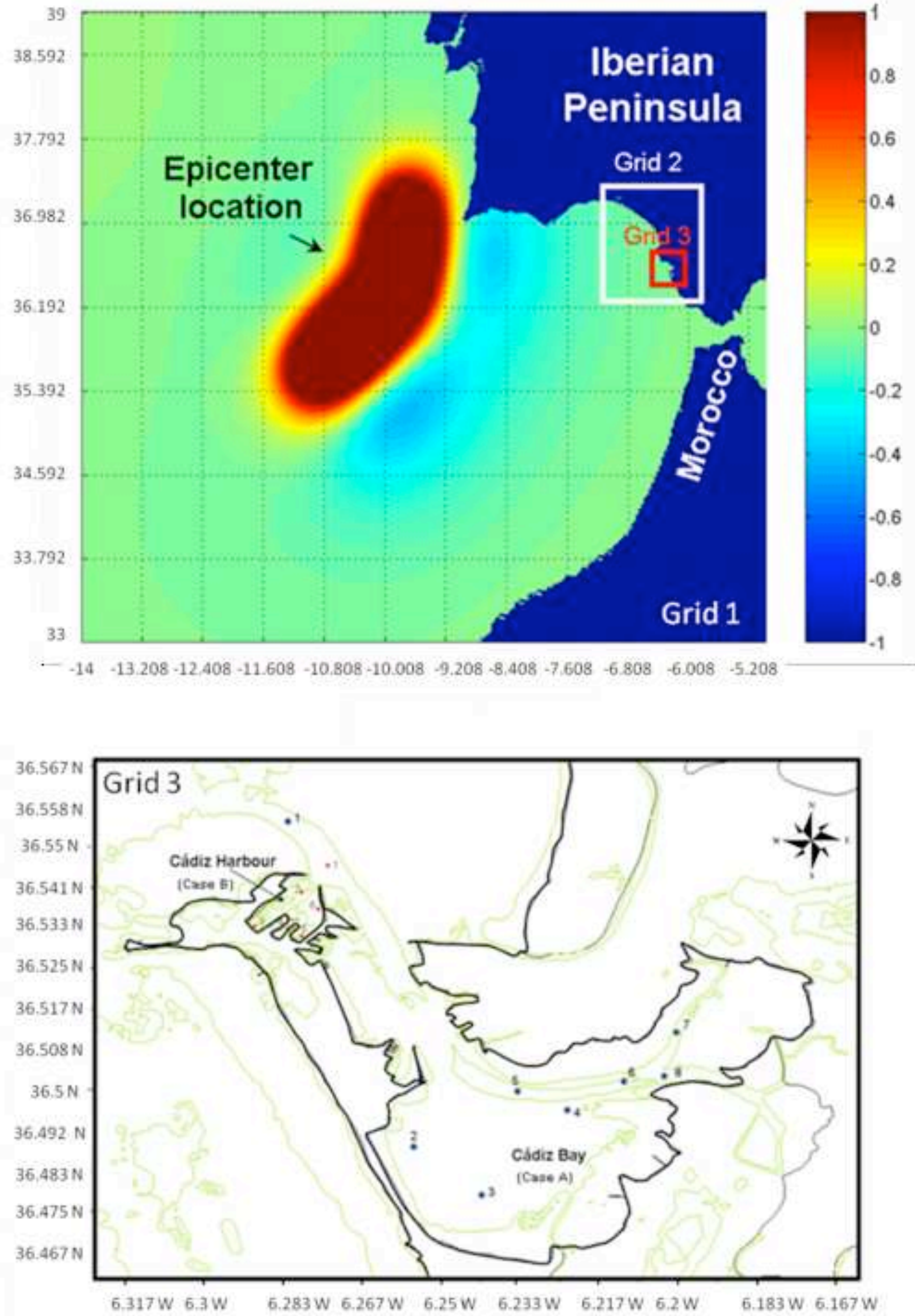


\section{Harbor control points}
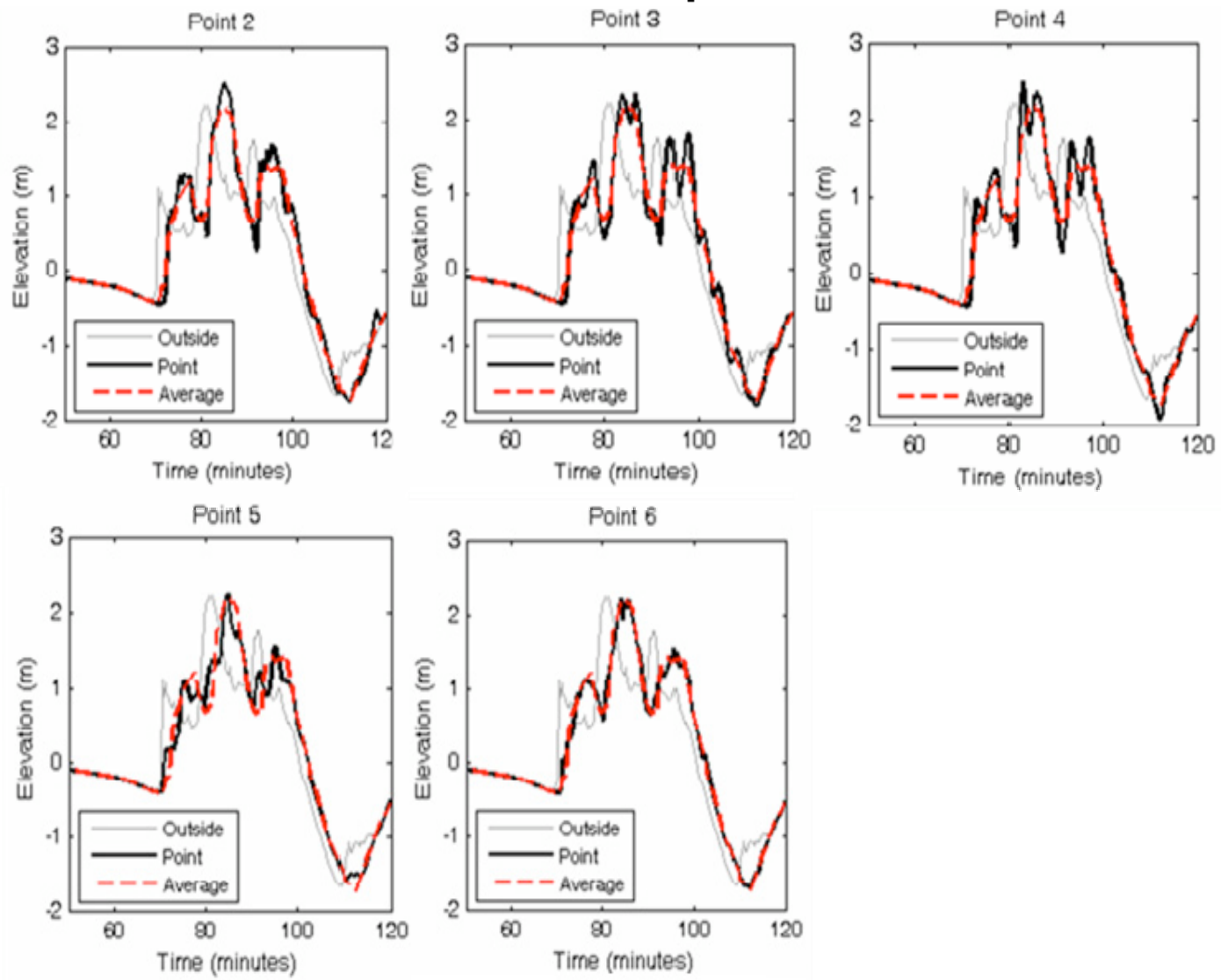

\section{Bay control points}
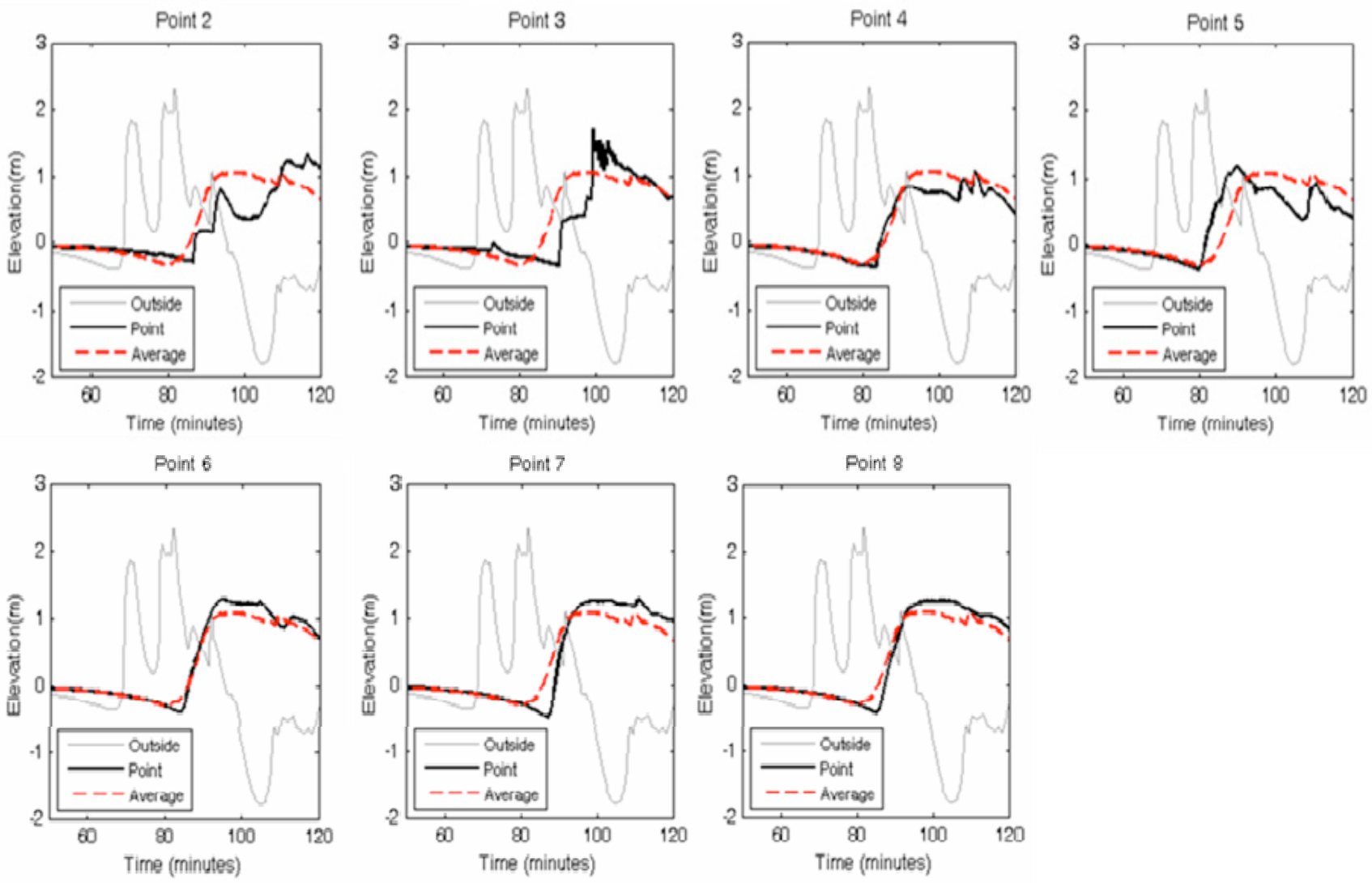

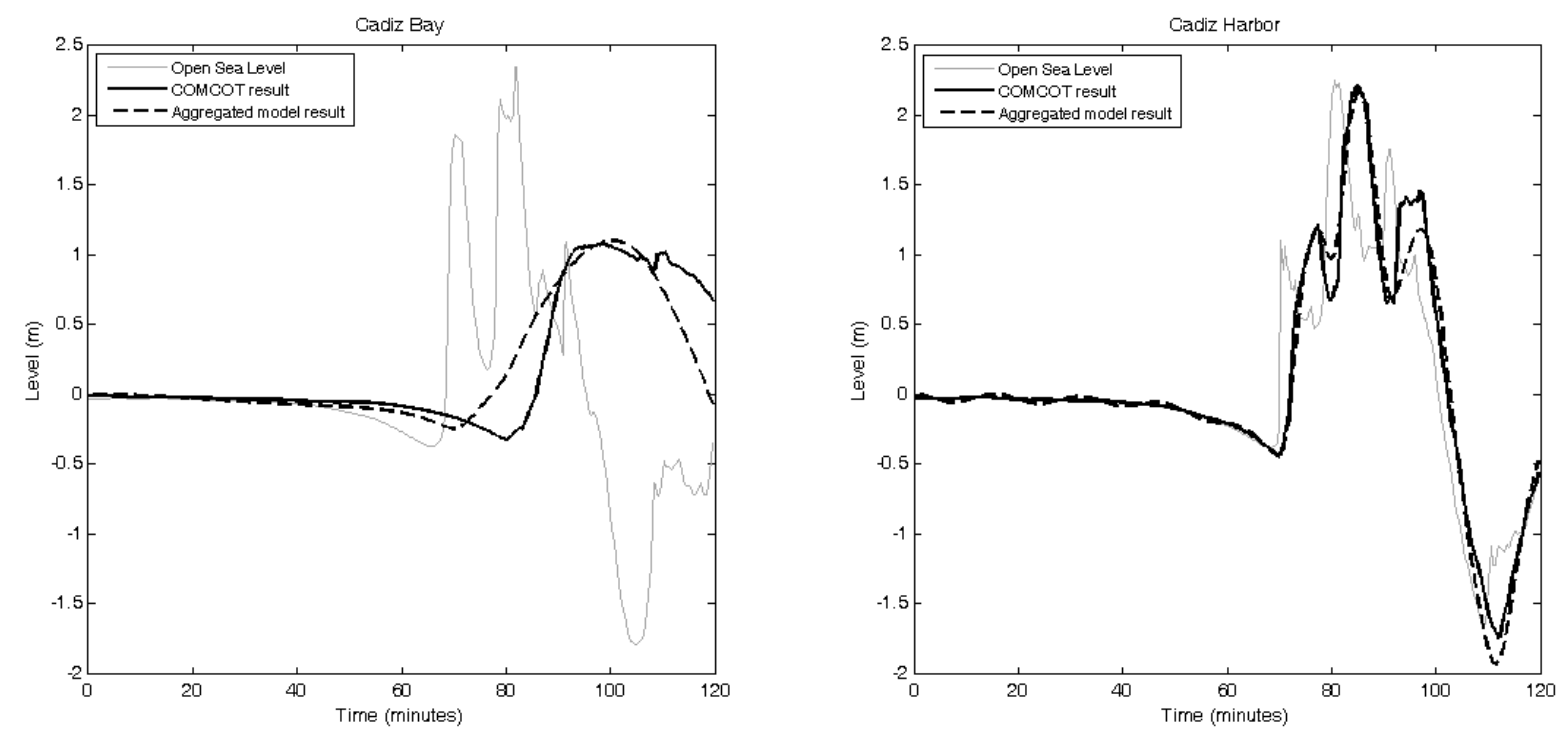